\title{
CSF studies on the relationship between dopamine and 5-hydroxytryptamine in Parkinsonism and other movement disorders
}

\author{
D. L. W. D A V I D S N ${ }^{1}$, C E L I A M Y A T S, C. M A W D L EY, \\ I. A. P U L L A R ${ }^{2}$, A N D HELEN W I L O N \\ From the MRC Brain Metabolism Unit, Department of Pharmacology and Department of Medical \\ Neurology, University of Edinburgh, Edinburgh, Scotland
}

S U M M A R Y In Parkinson's disease, the concentration of homovanillic acid (HVA) was reduced in lumbar CSF from patients with idiopathic Parkinsonism $(n=54, P<0.05)$ and post-encephalitic Parkinsonism $(n=19, P<0.01)$. The reduction in the concentrations of 5-hydroxyindolylacetic acid (5-HIAA) was not significant, and there was no alteration in the levels of 4-hydroxy-3methoxyphenylethylene glycol (MHPG). Treatment with L-dopa increased the concentration of HVA in the CSF $(\mathrm{P}<0.05)$ but had no effect on the levels of 5-HIAA and MHPG. Carbidopa given in combination with L-dopa produced similar CSF concentrations of dopa as did L-dopa alone but caused less than half the rise in HVA. Fourteen patients who became functionally independent on treatment with L-dopa had higher 5-HIAA levels than 23 patients who showed no such improvement $(\mathrm{P}<0.001)$, suggesting that intact 5-hydroxytryptamine neurones may be important in the therapeutic response to L-dopa. In a variety of movement disorders, the levels of HVA, 5-HIAA, and MHPG were not significantly different from age-matched controls. Treatment with tetrabenazine did not significantly alter the metabolite levels in patients in whom it produced either improvement, or side effects.

Numerous studies have shown that the concentration of homovanillic acid (HVA), the major metabolite of dopamine in the brain, is decreased in CSF in Parkinsonism (Johansson and Roos, 1965, 1974; Pullar et al., 1970; Chase and Ng, 1972; Rinne et al., 1973). However, the concentration of 5hydroxyindolylacetic acid (5-HIAA), the major metabolite of 5-hydroxytryptamine $(5-\mathrm{HT})$, has been more variably reported to be normal (Pullar et al., 1970; Parkes et al., 1971) or decreased (Gumpert et al., 1973). The relationship between the CSF concentrations of HVA and 5-HIAA and the subsequent clinical response to L-dopa could indicate the importance of dopamine and 5-HT in Parkinsonism. This relationship has been examined in the present study. The role of noradrena-

\footnotetext{
1 Present address: Department of Neurology, PO Box 72. Royal Infirmary, Dundee DD1 9ND, Scotland.

${ }^{2}$ Present address: Lilly Research Centre, Erl Wood Manor, Windlesham, Surrey.

Address for reprint requests: Celia M. Yates, Department of Pharmacology, 1 George Square, Edinburgh, EH8 9JZ, Scotland.

Accepted 9 August 1977
}

line in Parkinsonism is uncertain. The concentration of the major noradrenaline metabolite in brain, 4-hydroxy-3-methoxyphenylethylene glycol (MHPG) has, therefore, been measured in CSF from Parkinsonism patients before and after treatment with L-dopa and L-dopa in combination with the peripheral decarboxylase inhibitor, carbidopa.

The levels of the monoamine metabolites in CSF of patients with various involuntary movement disorders are reported. We have also studied the effect of tetrabenazine in these patients.

\section{Patients and methods}

LUMBAR PUNCTURE PROCEDURE AND BIOCHEMICAL ESTIMATIONS

All lumbar punctures (LPs) were performed at midday in patients who had been recumbent and fasting for at least 12 hours. Patients who were receiving phenothiazines, antihypertensive drugs, salicylates, antidepressants, and barbiturates were excluded. The first $5 \mathrm{ml}$ of CSF was taken, as described by Davidson et al. (1977), into glass 
test tubes for metabolite analysis and was immediately frozen and stored at $-20^{\circ} \mathrm{C}$ until the estimations were carried out.

HVA, 5-HIAA, and dopa were estimated fluorimetrically (Guldberg and Yates, 1968; Davidson et al., 1977). 'Total' 4-hydroxy-3-methoxyphenylethylene glycol (MHPG) was measured by gas-liquid chromatography after incubation with a sulphatase preparation to hydrolyse MHPG sulphate (Davidson et al., 1977).

\section{CONTROLS}

Fifteen patients with migraine, tension headache, diabetic neuropathy, ocular myopathy, or lumbar disc disease who were having LPs as part of their routine clinical investigation, as well as three healthy physicians, served as control subjects. None of the patients with lumbar disc disease showed evidence of restricted CSF flow to the lumbar sac. Of these 18 controls, five, with a mean age of $61 \pm 8$ years, were used as controls for the Parkinsonism patients who had a mean age of $62 \pm 8$ years. The 18 controls were divided into three age groups which corresponded to the ages of (1) the senile chorea patients, (2) the Huntington's chorea and spasmodic torticollis patients, and (3) the congenital choreoathetosis, dystonia musculorum deformans, and Wilson's disease patients, respectively.

\section{PATIENTS}

Parkinsonism Fifty-six patients suffering from the idiopathic form of the disease and 20 patients with postencephalitic Parkinsonism were studied. Samples of lumbar CSF were taken from these patients before treatment with L-dopa, or L-dopa plus carbidopa. Fifteen patients who were receiving anticholinergic drugs were maintained on these drugs throughout the whole investigation. Clinical evaluations were made by a neurologist who was unaware of the CSF results. The severity of hypokinesis, rigidity, and tremor were respectively graded as none, mild, moderate, severe. To 73 of the Parkinsonism patients L-dopa, $0.5 \mathrm{~g}$ daily, was introduced and increased gradually over at least two weeks. When an optimal dose was reached the LP was repeated in 37 patients. The response to L-dopa was assessed as intolerant-that is, unacceptable side effects; unresponsive-no observable improvement; grade 1 -observable but functionally insignificant improvement; grade 2functional improvement but remaining dependent; grade 3-good response, functionally independent. Nine patients were given L-dopa $625 \mathrm{mg}$ daily, in combination with carbidopa, $62.5 \mathrm{mg}$ daily, for two to four weeks before a further LP was performed.

Involuntary movement disorders Lumbar punctures were performed on 32 patients with various movement disorders (Table 1). Eleven patients had a repeat LP three weeks later when established on tetrabenazine in the optimal dose for reducing involuntary movements without unacceptable side effects.

\section{Results}

The concentrations of HVA, 5-HIAA, and MHPG in lumbar CSF in Parkinsonism are shown in Tables 2 and 3 and the results for involuntary

Table 1 Concentrations of HVA, 5-HIAA, and MHPG in lumbar CSF from patients with various involuntary movement disorders, and the effect of tetrabenazine

\begin{tabular}{|c|c|c|c|c|c|}
\hline & & \multicolumn{4}{|c|}{ Mean $\pm S D(n)$} \\
\hline & & \multirow{2}{*}{$\begin{array}{l}\text { Age } \\
(y r)\end{array}$} & \multicolumn{3}{|l|}{$n g / m l$} \\
\hline & & & $H V A$ & 5-HIAA & $M H P G$ \\
\hline \multicolumn{2}{|l|}{$\begin{array}{l}\text { Disorder } \\
\text { Control } \\
\text { Senile chorea }\end{array}$} & $\begin{array}{l}66 \pm 4(4) \\
70 \pm 5(7)\end{array}$ & $\begin{array}{l}40 \pm 19(3) \\
67 \pm 27(7)\end{array}$ & $\begin{array}{l}18 \pm 3(3) \\
26 \pm 10(7)\end{array}$ & $\begin{array}{r}6 \pm 2(3) \\
11 \pm 5(9)\end{array}$ \\
\hline \multicolumn{2}{|c|}{$\begin{array}{l}\text { Control } \\
\text { Huntington's chorea } \\
\text { Spasmodic torticollis }\end{array}$} & $\begin{array}{l}47 \pm 5(6) \\
49 \pm 13(13) \\
50 \pm 7(4)\end{array}$ & $\begin{array}{l}31 \pm 13(5) \\
31 \pm 17(13) \\
48 \pm 12(4)\end{array}$ & $\begin{array}{l}21 \pm 10(7) \\
20 \pm 13(13) \\
12 \pm 8(4)\end{array}$ & $\begin{array}{l}15 \pm 7(4) \\
\overline{9} \pm 3(4)\end{array}$ \\
\hline \multicolumn{2}{|c|}{$\begin{array}{l}\text { Control } \\
\text { Congenital choreoathetosis } \\
\text { Dystonia musculorum deformans } \\
\text { Wilson's disease }\end{array}$} & $\begin{array}{l}31 \pm 5(8) \\
28 \pm 7(4) \\
25 \pm 1(2) \\
16 \pm 22(2)\end{array}$ & $\begin{array}{l}23 \pm 7(8) \\
25 \pm 6(3) \\
17 \pm 18(2) \\
21 \pm 35(2)\end{array}$ & $\begin{array}{r}17 \pm 7(8) \\
9 \pm 3(3) \\
15 \pm 12(2) \\
4 \pm 11(2)\end{array}$ & $\begin{array}{l}8 \pm 3(5) \\
9(1) \\
23(1) \\
17(1)\end{array}$ \\
\hline \multicolumn{3}{|c|}{$\begin{array}{ll}\text { Effect of tetrabenazine } & \\
\text { Less than } 100 \mathrm{mg} / \text { day } & \text { Pretreatment } \\
& \text { Treatment }\end{array}$} & $\begin{array}{l}41 \pm 18(5) \\
42 \pm 16(5)\end{array}$ & $\begin{array}{l}16 \pm 4(5) \\
19 \pm 6(5)\end{array}$ & $\begin{array}{l}13 \pm 6(9) \\
14 \pm 15(9)\end{array}$ \\
\hline More than $100 \mathrm{mg} /$ day & $\begin{array}{l}\text { Pretreatment } \\
\text { Treatment }\end{array}$ & & $\begin{array}{l}41 \pm 18(6) \\
26 \pm 22(6)\end{array}$ & $\begin{array}{r}14 \pm 7(4) \\
9 \pm 4(4)\end{array}$ & - \\
\hline
\end{tabular}

- indicates no estimate 
Table 2 Concentrations of HVA, 5-HIAA, and MHPG in lumbar CSF in idiopathic and postencephalitic Parkinsonism before and after treatment with L-dopa alone or in combination with carbidopa

\begin{tabular}{|c|c|c|c|c|c|}
\hline \multirow[t]{3}{*}{ Group } & \multicolumn{5}{|c|}{$M e a n \pm S D(n)$} \\
\hline & \multirow{2}{*}{$\begin{array}{l}\text { Age } \\
(y r)\end{array}$} & \multicolumn{4}{|l|}{$n g / m l$} \\
\hline & & $H V A$ & $5-H I A A$ & $M H P G$ & $D O P A$ \\
\hline Control & $61 \pm 8(5)$ & $38 \pm 19(5)$ & $20 \pm 12(5)$ & $7 \pm 3(3)$ & \\
\hline $\begin{array}{l}\text { Parkinson's disease } \\
\text { Before L-dopa treatment } \\
\text { Idiopathic } \\
\text { Post-encephalitic } \\
\text { All }\end{array}$ & $\begin{array}{l}63 \pm 8(56) \\
58 \pm 5(20) \\
62 \pm 8(76)\end{array}$ & $\begin{array}{l}22 \pm 14^{*}(54) \\
15 \pm 10+(19) \\
20 \pm 30(73)\end{array}$ & $\begin{array}{l}14 \pm 9(55) \\
13 \pm 7(19) \\
14 \pm 8(74)\end{array}$ & $\begin{array}{l}9 \pm 5(18) \\
7 \pm 3(7) \\
8 \pm 5(25)\end{array}$ & \\
\hline $\begin{array}{l}\text { After L-dopa treatment } \\
\text { L-dopa alone } \\
\text { L-dopa + carbidopa }\end{array}$ & & $\begin{array}{c}198 \pm 169 *(37) \\
62 \pm 65(9)\end{array}$ & $\begin{array}{l}13 \pm 10(37) \\
10 \pm 8(9)\end{array}$ & $\begin{array}{r}10 \pm 5(7) \\
9 \pm 5(4)\end{array}$ & $\begin{array}{r}112 \pm 57(7) \\
95 \pm 20(8)\end{array}$ \\
\hline
\end{tabular}

$\left.\begin{array}{l}{ }^{*} \mathrm{P}<0.05 \\ \dagger \mathrm{P}<0.01\end{array}\right\}$ compared with controls.

Other values not significantly different $(P>0.05)$ from controls.

Table 3 Concentrations of HVA and 5-HIAA in lumbar CSF from patients with Parkinsonism in relation to their subsequent response to $L$-dopa therapy

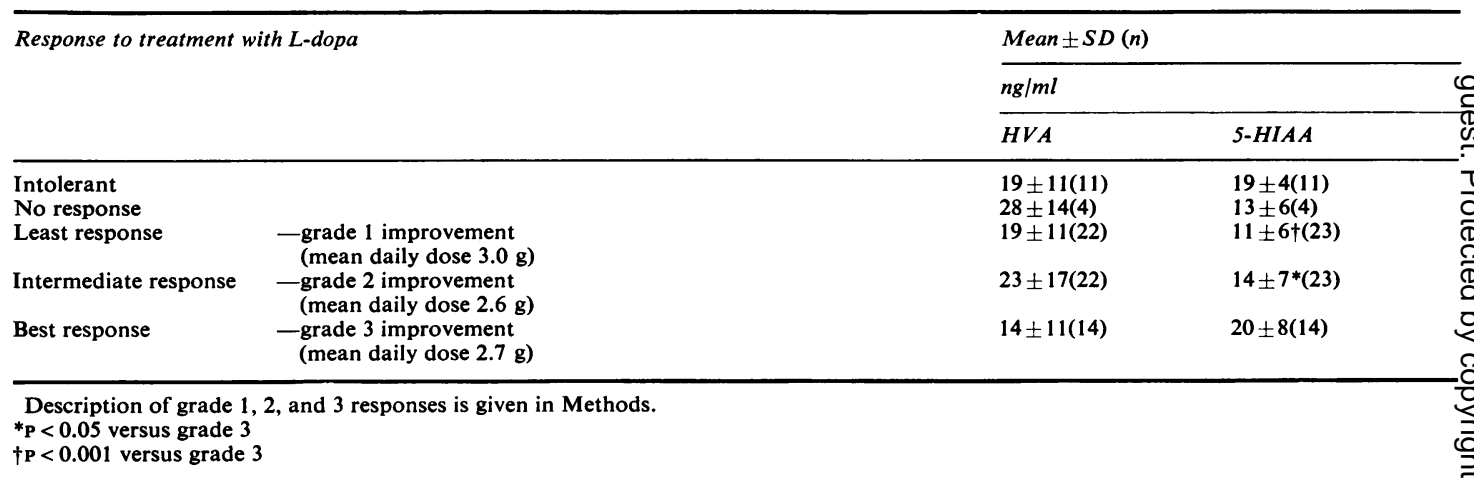

movement disorders in Table 1. All statistical comparisons were made using Student's $t$ test and $\mathbf{P}$ values of $\leqslant 0.05$ were taken to indicate a significant difference.

\section{PARKINSONISM}

The HVA concentrations were lower in patients with idiopathic Parkinson's disease than in controls $(P<0.05)$, and were lower still in patients suffering from postencephalitic Parkinsonism $(P<0.01)$. The concentrations of 5-HIAA and MHPG in both forms of Parkinsonism were not significantly different from control values (Table 2). There was no correlation of duration of Parkinsonism, severity of hypokinesis, rigidity, or tremor with HVA, 5-HIAA, or MHPG concentrations. The concentrations of metabolites in CSF from patients receiving anticholinergic drugs did not differ from the concentrations in patients not given anticholinergics. There was no difference between the proportion of patients receiving anticholinergics in the patient groups shown in Table 2.
Treatment with L-dopa produced an increase $(P<0.05)$ in HVA which was greater than the increase, which did not reach significance, in HVA produced by treatment with L-dopa in combination with carbidopa. The concentrations of dopa in the CSF were similar after both treatments. Administration of L-dopa by itself or with carbidopa had no effect on the concentrations of 5-HIAA or MHPG in the CSF (Table 2). In patients given L-dopa alone, the increase in the concentration of HA in the CSF correlated with the dose of L-dopa $(r=0.54, \mathrm{P}<0.05)$ but not with the therapeutic response.

Patients who showed the best (grade 3) response to treatment with L-dopa had higher pretreatment 5-HIAA concentrations than patients with an intermediate (grade 2) response and patients showing the least (grade 1) response (Table 3 ). The concentration of 5-HIAA in patients showing no response was markedly less than in patients with the best response, but this difference did not reach significance probably because of the small number 
of patients in the former group. The pretreatment concentrations of HVA, on the other hand, tended to be lower in patients with the best response to L-dopa than in patients with an intermediate response, patients with the least response, and patients showing no response. Within each response group, there was no difference between the concentrations of HVA and 5-HIAA in CSF from patients not receiving anticholinergics and from patients on anticholinergics. The number in some of these groups was, however, only two or three.

\section{INVOLUNTARY MOVEMENT DISORDERS}

There were marked differences in HVA and 5HIAA concentrations in different groups of disorders, but no group was significantly different from age-matched controls (Table 1). Tetrabenazine did not significantly alter the concentrations of HVA, 5-HIAA, and MHPG in the entire group, although there was some reduction in patients receiving doses of $100 \mathrm{mg}$ or more per day.

\section{Discussion}

\section{CONTROLS}

Selection of an appropriate control group is difficult since abnormalities of monoamine metabolites have been reported in a variety of neurological disorders. In our study the controls comprised three healthy physicians and a miscellaneous group of patients without major disorders of the CNS who had migraine, tension headaches, neuropathies, and lumbar disc disease. The heterogeneity of this group may contribute to the wide variation in results. Age-matched controls were used for the patients groups since we found, in common with others (Gottfries et al., 1971; Bowers, 1972), that the concentrations of HVA and 5-HIAA increased with age. Exercise increases HVA and 5HIAA concentrations in the CSF (Post et al., 1973), and failure to enforce recumbency before lumbar puncture results in higher HVA levels (Davidson et al., 1977). Patients were, therefore, kept recumbent for 12 hours before puncture. Withdrawal of a standard CSF volume of $5 \mathrm{ml}$ should avoid variations in metabolite levels related to the volume of CSF removed (Jakupčević et al., 1977).

\section{INVOLUNTARY MOVEMENT DISORDERS}

The concentrations of the amine metabolites in different movement disorders were not significantly different from age-matched controls. The observation that tetrabenazine, a synthetic benzoquinolizine derivative which depletes central monoamines, did not significantly alter HVA and
5-HIAA concentrations in CSF, despite clear clinical effects suggests that these estimations are of limited use in the study of involuntary movement disorders.

\section{PARKINSONISM}

Concentrations of $H V A$ Our findings confirm numerous previous reports that HVA concentrations in lumbar CSF are low in Parkinsonism (Johansson and Roos, 1965; Pullar et al., 1970; Rinne et al., 1973), and are lower in postencephalitic disease (Table 2). As the concentrations of HVA overlap with the normal range such estimations are of little value in the diagnosis of Parkinsonism. There was no correlation between the concentrations of HVA in CSF and the severity of hypokinesis, although in postmortem studies the reduction in HVA and dopamine in the caudate nucleus has been shown to be related to the degree of hypokinesis (Bernheimer et al., 1973). The present study confirms others (Parkes et al., 1971; Gumpert et al., 1973) in that there was no correlation between the concentrations of HVA and 5-HIAA and the severity of the clinical features of hypokinesis, rigidity, or tremor.

The HVA concentrations in CSF of patients with the best response to L-dopa were slightly but not significantly lower than in CSF from patients with a minimal response (Table 3 ). A negative correlation of pretreatment HVA concentration with response to L-dopa has been found by Lakke et al. (1971) using probenecid, and by Jéquier and Dufresne (1972). However, Chase and $\mathrm{Ng}$ (1971), Weiner and Klawans (1973), and Granerus et al. (1974), did not find CSF HVA a useful predictor of response to L-dopa. The small group of four Parkinsonism patients who had normal pretreatment HVA concentrations (Table 3), and who showed no clinical improvement and no side effects after large doses of L-dopa is a small, interesting group who may be metabolically different from other patients suffering from Parkinsonism. Our findings of a marked increase in HVA after L-dopa therapy (Table 2), confirms well-established observations (Godwin-Austen et al., 1971). The increase correlated with the dose of L-dopa but not with the therapeutic response. A smaller increase in the HVA concentration, unaccompanied by a change in the CSF dopa concentration, was found when L-dopa was given in combination with carbidopa. A possible explanation for this observation is that carbidopa, which inhibits peripheral dopa decarboxylase, may inhibit dopa decarboxylase in the cerebral blood vessels.

Concentrations of MHPG The concentration of MHPG in the CSF of idiopathic and postencepha- 
litic Parkinsonism patients did not differ from controls, despite the decreased noradrenaline concentration found in postmortem samples of caudate nucleus and hypothalamus taken from postencephalitic Parkinsonism patients (Ehringer and Hornykiewicz, 1960). Although L-dopa is a potential precursor of MHPG, loading with the amino acid did not alter the concentration of MHPG in the CSF. Similar results have been reported by Chase et al. (1973) and Wilk (1976). It is uncertain whether this arises from the constancy of brain noradrenaline turnover or the inadequacy of CSF estimation of MHPG as an index of noradrenaline turnover. The rapid diffusion of MHPG from CSF to blood (Wolfson and Escriva, 1976) supports the latter explanation.

Concentrations of 5-HIAA In agreement with the results of Pullar et al. (1970) and Parkes et al. (1971), but not those of Rinne et al. (1973) and Gumpert et al. (1973), we did not find significantly reduced concentrations of 5-HIAA in CSF despite the decreased 5-HT concentration found in the basal ganglia of patients suffering from Parkinsonism (Bernheimer et al., 1961). Chase and $\mathrm{Ng}(1971,1972)$, on the basis of probenecid loading of Parkinsonism patients, have suggested that the turnover rates of both dopamine and 5-HT are reduced in Parkinsonism. Chase (1974) suggested that the reduced turnover of 5-HT reflected a diminished function of 5-HT neurones which was secondary to a primary reduction in dopaminergic activity. If this were so, L-dopa treatment, which should increase the activity of dopaminergic neurones, might be expected to increase CSF 5HIAA. However, under these conditions we found no change in 5-HIAA; Van Woert and Bowers (1970) found a significant reduction in 5-HIAA after the administration of L-dopa.

The pretreatment 5-HIAA concentrations are of particular interest when related to the therapeutic response to L-dopa (Table 3). Good responders had significantly higher concentrations of 5HIAA than patients with an intermediate or poor response. The small group of patients showing no response to L-dopa also had lower 5-HIAA concentrations than the good responders, although the difference because of the small number did not reach statistical significance. There has been much discussion on the possibility that L-dopa treatment might modify 5-HT metabolism and that this change may be involved in the long-term effects of L-dopa therapy, but there has been little evidence that pretreatment 5-HT turnover might be an important determinant of therapeutic response to L-dopa. Investigations into the use of amine metabolite levels in the CSF as predictors of re- sponse to L-dopa have concentrated on HVA (Chase and $\mathrm{Ng}$, 1971; Lakke et al., 1971; Jéquier and Dufresne, 1972; Weiner and Klawans, 1973; Granerus et al., 1974). Gumpert et al. (1973), however, found a tendency for patients responding well to L-dopa to have high 5-HIAA concentrations. Our results suggest that the presence of intact 5-HT neurones may be important in the therapeutic response to L-dopa. Dopa may be decarboxylated in 5-HT neurones in man, as suggested by the accumulation of dopamine which occurs in 5-HT neurones in the rat after administration of dopa and a decarboxylase inhibitor (Butcher et al., 1970). An alternative explanation is that the reduced 5-HT turnover in Parkinsonism (Chase and $\mathrm{Ng}, 1971,1972$ ) is related to an impairment of 5-HT neurones, possibly the raphe-caudate fibres (Cools and Janssen, 1974), which is not secondary to a reduction in dopaminergic activity. Patients with very low CSF 5-HIAA concentrations, who did not respond well to L-dopa, might represent a group in whom loss of 5-HT function is moree important than loss of dopaminergic function These particular patients might respond to treat $\stackrel{?}{?}$ ment with 5-hydroxytryptophan despite evidence that this drug worsens Parkinsonism (Chase, 1970)

We are most grateful to Dr G. W. Ashcroft and Dr T. B. B. Crawford for discussion and advice and to Mrs Nancy Kinloch and Miss Eileerg Walker for careful technical assistance.

\section{References}

Bernheimer, H., Birkmayer, W., and Hornykiewicz, O. (1961). Verteilung des 5-hydroxy tryptamins (serotonin) im gehirn des menschen und sein verhalten bei patienten mit Parkinsonsyndrom. Klinische Wochenschrifte, 39, 1056-1059.

Bernheimer, H., Birkmayer, W., Hornykiewicz, O., Jellinger, K., and Seitelberger, F. (1973). Brain dopamine and the syndrome of Parkinson and Huntington. Clinical morphological and neurochemical correlations. Journal of the Neurological Sciences, 20, 415-455.

Bowers, M. B. (1972). Clinical measurements of central dopamine and 5-hydroxytryptamine metabolism: reliability and interpretation of cerebrospinal fluid acid monoamine metabolite measures. Neuropharmacology, 11, 101-111.

Butcher, L., Engel, J., and Fuxe, K. (1970). L-dopa induced changes in central monoamine neurons after peripheral decarboxylase inhibition. Journal of Pharmacy and Pharmacology, 22, 313-316.

Chase, T. N. (1970). 5-Hydroxytryptophan in Parkinsonism. Lancet, 1, 1029-1030.

Chase, T. (1974). Serotonergic-clopaminergic interactions and extrapyramidal function. In Advances 
in Biochemical Psychopharmacology II, pp. 377-385. Raven Press: New York.

Chase, T. N., Gordon, E. K., and Ng, L. K. Y. (1973). Norepinephrine metabolism in the central nervous system of man: studies using 3-methoxy-4-hydroxyphenylethylene glycol levels in cerebrospinal fluid. Journal of Neurochemistry, 21, 581-587.

Chase, T., and Ng, L. K. Y. (1971). Probenecid test in Parkinson's disease. Lancet, 2, 1265-1266.

Chase, T., and Ng, L. K. Y. (1972). Central monamine metabolism in Parkinson's disease. Archives of Neurology (Chicago), 22, 479-484.

Cools, A. R., and Janssen, H-J. (1974). The nucleus linearis intermedius raphe and behavior evoked by direct and indirect stimulation of clopamine sensitive sites within the caudate nucleus of cats. Journal of Neurochemistry, 28, 66-275.

Davidson, D. W., Pullar, I. A., Mawdsley, C., Kinloch, N., and Yates, C. M. (1977). Monoamine metabolites in cerebrospinal fluid in multiple sclerosis. Journal of Neurology, Neurosurgery, and Psychiatry, 40, 741-745.

Ehringer, H., and Hornykiewicz, O. (1960). Verteilung von noradrenalin und dopamin (3-hydroxytyramin) im gehirn des menschen und ihr verhalten bei erkrankungen des extrapyramidalen systems. Klinische Wochenschrifte, 38, 1236-1239.

Godwin-Austen, R. B., Kantamaneni, B. D., and Curzon, G. (1971). Comparison of benefit of L-dopa in Parkinsonism with increase of amine metabolites in the CSF. Journal of Neurology, Neurosurgery, and Psychiatry, 34, 219-223.

Gottfries, C. G., Gottfries, I., Johansson, B., Olsson, R., Persson, T., Roos, B-E., and Sjöstrom, R. (1971). Age monoamine metabolites in human CSF and their relations to age and sex. Neuropharmacology, 10, 665-672.

Granerus, A. K., Magnusson, T., Roos, B-E., and Svanborg, A. (1974). Relationship of age and mood to monoamine metabolites in cerebrospinal fluid in Parkinsonism. European Journal of Clinical Pharmacology, 7, 105-109.

Guldberg, H. C., and Yates, C. M. (1968). Some studies of the effects of chlorpromazine, reserpine and dihydroxyphenylalanine on the concentrations of homovanillic acid, 3,4-dihydroxyphenylacetic acid and 5-hydroxyindol-3-ylacetic acid in ventricular cerebrospinal fluid of the dog using the techniques of serial sampling of the cerebrospinal fluid. British Journal of Pharmacology, 33, 457-471.

Gumpert, J., Sharpe, D., and Curzon, G. (1973). Amine metabolites in the cerebrospinal fluid in Parkinson's disease and the response to levodopa. Journal of the Neurological Sciences, 19, 1-12.

Jakupčević, M., Lacković, Stefoski, D., and Bulat, M. (1977). Non-homogeneous distribution of 5- hydroxyindolylacetic acid and homovanillic acid in the lumbar CSF of man. Journal of the Neurological Sciences, 31, 165-171.

Jéquier, E., and Dufresne, J-J. (1972). Biochemical investigations in patients with Parkinson's disease treated with L-dopa. Neurology (Minneapolis), 22, 15-21.

Johansson, B., and Roos, B-E. (1965). Acid metabolites in the cerebrospinal fluid of patients with Parkinson's syndrome. Proceedings of the 8th International Congress of Neurology, Vienna, IV/I, 141-144.

Johansson, B., and Roos, B-E. (1974). 5-Hydroxyindole acetic acid and homovanillic acid in cerebrospinal fluid of patients with neurological diseases. European Neurology, II, 37-45.

Lakke, J. P. W. F., Korf, J., and Van Praag, H. M. (1971). Predicting response to levodopa. Lancet, 2, 164-165.

Parkes, J. D., Baxter, R. C. H., Curzon, G., KnillJones, R. P., Knott, P. J., Marsden, C. D., Tattersall, R., and Vollum, D. (1971). Treatment of Parkinson's disease with amantadine and levodopa. Lancet, 1, 1083-1086.

Post, R. M., Kotin, J., Godwin, F. K., and Gordon, E. K. (1973). Psychomotor activity and cerebrospinal fluid amine metabolites in affective illness. American Journal of Psychiatry, 130, 67-72.

Pullar, I. A., Weddell, J. M., Ahmed, R., and Gillingham, F. J. (1970). Phenolic acid concentrations in the lumbar cerebrospinal fluid of Parkinsonian patients treated with 1-dopa. Journal of Neurology, Neurosurgery, and Psychiatry, 33, 851-857.

Rinne, U. K., Sonninen, V., and Siirtola, T. (1973). Acid monoamine metabolites in the cerebrospinal fluid of Parkinsonian patients treated with levodopa alone or combined with a decarboxylase inhibitor. European Neurology, 9, 349-362.

Van Woert, M. H., and Bowers, M. B. (1970). The effect of L-dopa on monoamine metabolites in Parkinson's disease. Experientia (Basel), 26, 161-163.

Weiner, W. J., and Klawans, H. L. (1973). Failure of cerebrospinal fluid homovanillic acid to predict levodopa response in Parkinson's disease. Journal of Neurology, Neurosurgery, and Psychiatry, 36, 747752.

Wilk, S. (1976). Metabolism of biogenic amines in the CNS of man. In Proceedings of the Sixth International Congress of Pharmacology. Edited by J. Tuomisto and M. K. Paasonen, Vol. 3, pp. 245-254. Pergamon Press: Oxford.

Wolfson, L. I., and Escriva, A. (1976). Clearance of 3-methoxy-4-hydroxyphenylglycol from the cerebrospinal fluid. Neurology (Minneapolis), 26, 781784. 